\title{
Fluorophilic-lipophilic-hydrophilic poly-2-oxazolines block copolymers as MRI contrast agents: from synthesis to self-assembly
}

Leonid I. Kaberov ${ }^{1}$, Bart Verbraeken ${ }^{2}$, Anna Riabtseva ${ }^{1}$, Jiri Brus ${ }^{1}$, Aurel Radulescu ${ }^{3}$, Yeshayahu Talmon ${ }^{4}$, Petr Stepanek ${ }^{1}$, Richard Hoogenboom ${ }^{2}$, Sergey K. Filippov ${ }^{{ }^{*}}$

${ }^{1}$ Institute of Macromolecular Chemistry, Academy of Sciences of the Czech Republic, Heyrovský Sq. 2, 16206 Prague 6, Czech Republic

${ }^{2}$ Supramolecular Chemistry Group, Centre of Macromolecular Chemistry (CMaC), Department of Organic and Macromolecular Chemistry, Ghent University, Krijgslaan 281 S4, B-9000 Ghent, Belgium

${ }^{3}$ Forschungszentrum Jülich GmbH, Jülich Centre for Neutron Science JCNS, Outstation at Heinz Maier-Leibnitz Zentrum, Lichtenbergstraße 1, 85748 Garching, Germany

${ }^{4}$ Department of Chemical Engineering, Technion-Israel Institute of Technology, Haifa 3200003, Israel

*e-mail: filippov@imc.cas.cz

\begin{abstract}
This work focused on the synthesis and self-assembly of triphilic poly(2-oxazoline) triblock copolymers with high fluorine content towards our future aim of developing poly(2-oxazoline) MRI contrast agents. A highly fluorinated 2-substituted-2-oxazoline monomer, namely 2$(1 \mathrm{H}, 1 \mathrm{H}, 2 \mathrm{H}, 2 \mathrm{H}$-perfluorooctyl)-2-oxazoline was synthesized using the Grignard reaction. The polymerization kinetics of the synthesized monomer was studied and it was used for the preparation of triblock copolymers with hydrophilic 2-methyl-2-oxazoline, hydrophobic 2octyl-2-oxazoline and fluorophilic blocks by Cationic Ring-Opening Polymerization yielding polymer with low relatively dispersity (1.2-1.4). The presence of the blocks with the different nature in one copolymer structure facilitated self-assembly of the copolymers in water and dimethylsulfoxide as observed by dynamic light scattering, cryo-transmition electron microscopy, and small-angle neutron scattering. The nanoparticle morphology is strongly influenced by the order and length of each block and the nature of solvent, leading to nanoparticles with core-shell structure as confirmed by small angle neutron scattering. The reported poly(2-oxazoline) block copolymers with high fluorine content have high potential for future development of MRI contrast agents.
\end{abstract}


Key-words: poly(2-oxazoline)s, fluorine, Grignard reaction, self-assembly, DLS, SANS, CryoTEM, MRI

\section{INTRODUCTION}

Since the first time that the cationic ring-opening polymerization (CROP) of 2oxazolines was described in $1966,{ }^{1-4}$ this method became a popular approach for the controlled synthesis of self-assembling polymer systems. Under appropriate conditions the CROP proceeds in a living mode, which makes it very useful for the synthesis of block copolymers. Although it requires extreme purity of all components (lack of moisture and any nucleophilic impurities), the CROP of 2-oxazolines allows to obtain polymers with very low dispersity. By variation of the 2-oxazoline substituent one can obtain hydrophilic, hydrophobic, fluorophilic and various stimuli-responsive polymers (or blocks). ${ }^{5}$

The self-assembly of hydrophilic-hydrophobic block copolymers in solutions is already studied in detail. ${ }^{6-9}$ Nowadays there is a continuous quest for block copolymers that contain two immiscible hydrophobic moieties to further sophisticate their self-assembly. One of the options is to combine lipophilic and fluorophilic fragments in one polymer. Despite their similar structure, alkyl chains and their fluorinated analogues possess quite different behavior in terms of solubility, flexibility, and polarizability. ${ }^{10}$ Also fluorinated substances are promising as contrast agents in ${ }^{19} \mathrm{~F}$ magnetic resonance imaging (MRI). Fluorine atoms have high MR sensitivity and ${ }^{19} \mathrm{~F}$ MRI has virtually no background signal since the fluorine in body occurs almost exclusively in bones. ${ }^{11-13}$

The additional ordering of polymers containing more than two thermodynamically incompatible blocks in aqueous solutions was nicely demonstrated by Hilmyer, Lodge and coworkers. ${ }^{14}$ The investigation of multicompartment micelles formed by linear styrene-based ABC-triblock copolymers have been also reported by Laschewsky et.al.. ${ }^{15,16}$ The majority of fluorine-containing polymers reported in literature is based on poly(meth)acrylates. ${ }^{17-23}$

The synthesis of poly-2-oxazolines with fluorophilic blocks suffers from the difficulties of synthesis and polymerization of fluorophilic monomers. The deceleration effect of the 
perfluoroalkyl substituent in 2-substituted-2-oxazoline was described by Saegusa and coworkers. ${ }^{24}$ The polymerization of these monomers is time-consuming and requires high temperatures leading to poor control. ${ }^{24-26}$

Nevertheless, several examples of other fluorine containing 2-oxazoline based polymers are known. Perfluoroalkyl fragments could be incorporated during initiation or termination of CROP. The synthesis of PMeOx-based polymeric surfactants with $\mathrm{C}_{8} \mathrm{~F}_{17} \mathrm{CH}_{2} \mathrm{CH}_{2}$ terminal group using initiator-based modification was described for the first time by Nuyken and coworkers. ${ }^{27}$ Later this method was used for the synthesis of $\mathrm{ABC}$ triblock copolymers endcapped with perfluoroalkyl and regular alkyl chains by initiation and termination respectively. ${ }^{28}$ The small-angle X-ray scattering study had shown that these chain-end functionalized polymers self-assembled into cylindrical micelles with hypothetical multicompartment structure of the micellar core. Another approach for functionalization of poly(2-oxazoline)s by CROP termination with perfluorocarboxylic acids was described by Kaberov et.al. ${ }^{29}$

A detailed study of the polymerization kinetics of fluorinated 2-phenyl-2-oxazolines was reported by Schubert. ${ }^{30}$ The ABC triblock copolymers with 2-difluorophenyl-2-oxazoline block was found to form aggregates of unique rolled-up cylindrical morphology in aqueous milieu. ${ }^{31}$ The synthesis of amphiphilic block copolymers of $2-1 \mathrm{H}, 1 \mathrm{H}, 2 \mathrm{H}, 2 \mathrm{H}$-perfluorohexyl-2-oxazoline and 2-methyl-2-oxazoline was provided by Jordan and co-workers. ${ }^{25}$ Small-angle neutron scattering and Transmission Electron Microscopy (TEM) study proved the formation of elongated micelles in aqueous solution for these copolymers. Recently, we reported a detailed study of increasing the polymerization reactivity of fluorophilic 2-oxazolines by the insertion of alkyl spacers between a fluorinated substituent and the 2-oxazoline ring. ${ }^{32}$ By this approach we suggested a new platform for the synthesis of a variety of triblock copoly(2-oxazoline)s with fluorinated blocks.

In the current work we tested the classical approaches for the synthesis of the highly fluorinated 2- $\left(1 \mathrm{H}, 1 \mathrm{H}, 2 \mathrm{H}, 2 \mathrm{H}\right.$-perfluorooctyl)-2-oxazoline $\left(\mathrm{R}_{\mathrm{f}}{ }^{6} \mathrm{EtOx}\right)$ monomer. On the basis of these unsuccessful attempts, we suggest an alternative pathway for the synthesis of this monomer based on a Grignard reaction step to make the perfluoralkyl acid and studied its polymerization kinetics. The insertion of a double methylene spacer significantly increases the monomer reactivity in the polymerization reaction. Further, we describe the synthesis of new poly(2oxazoline) di- and triblock copolymers with mutually immiscible hydrophilic, hydrophobic and fluorophilic blocks. In the last part of the paper we present the self-assembly behaviour of the 
copolymers by Dynamic Light Scattering (DLS), Small-angle Neutron Scattering (SANS), and Cryo-Transmission Electron Microscopy (Cryo-TEM).

\section{MATERIALS AND METHODS}

\subsection{Materials}

2-Methyl-2-oxazoline (MeOx, $99 \%$, Acros Organics) was dried over $\mathrm{BaO}$ and distilled before use. Triethylamine (TEA, >99\%, Fisher Scientific) was dried over $\mathrm{CaH}_{2}$ and distilled under reduced pressure. n-Nonanoic acid, 2-chloroethylamine hydrochloride, 18-crown-6-ether, and thionyl chloride were purchased from Acros Organics and used as received. 2Bromoethylamine hydrobromide was purchased from Sigma-Aldrich and used as received. Methyl p-toluenesulfonate (Sigma-Aldrich) was distilled under reduced pressure before use. $1 \mathrm{H}, 1 \mathrm{H}, 2 \mathrm{H}, 2 \mathrm{H}$-perfluorooctyl iodide was purchased from Fluorochem Limited and used as received. Dichloromethane (DCM, Lachner) was dried by refluxing over phosphorus pentoxide and distilled before use. Tetrahydrofuran (THF, Lachner) was dried by refluxing over $\mathrm{CaH}_{2}$ and distilled before use. Acetonitrile (ACN, Lachner) was dried by refluxing over $\mathrm{BaO}$ and distilled before use. Ethyl acetate (EtAc, Lachner) was dried over $\mathrm{CaCl}_{2}$ and distilled before use. MilliQ water was prepared by MilliPore Milli-Q® Gradient installation. All other chemicals were used as received.

\subsection{Monomer synthesis}

\subsubsection{Synthesis of n-nonanoic acid chloride}

$n$-Nonanoic acid (10 g, $0.063 \mathrm{~mol})$ was dissolved in dry DCM $(50 \mathrm{ml})$. The mixture was cooled down in an ice bath. After that, thionyl chloride $(7 \mathrm{ml}, 0.096 \mathrm{~mol})$ was added dropwise. The mixture was stirred at $40{ }^{\circ} \mathrm{C}$ overnight. Next, DCM and excess thionyl chloride were removed under reduced pressure. The residue was distilled under reduced pressure yielding pure product as a colourless liquid. Yield=11 g $(98 \%) .{ }^{1} \mathrm{H}$ NMR $\left(300 \mathrm{MHz}, \mathrm{CDCl}_{3}\right) \delta 2.88(\mathrm{t}, \mathrm{J}=7.3 \mathrm{~Hz}$, $\left.\mathrm{CH}_{2}-\mathrm{C}(\mathrm{O}) \mathrm{Cl}, 2 \mathrm{H}\right), 1.69$ (m, $\left.-\mathrm{CH}_{2}-\mathrm{CH}_{2}-\mathrm{C}(\mathrm{O}) \mathrm{Cl}, 2 \mathrm{H}\right), 1.27\left(\mathrm{~m}, \mathrm{CH}_{3}\left(\mathrm{CH}_{2}\right)_{5}-, 10 \mathrm{H}\right), 0.88$ (t, J = $\left.6.7 \mathrm{~Hz}, \mathrm{CH}_{3^{-}}, 3 \mathrm{H}\right)$.

\subsubsection{Synthesis of N-(2-chloroethyl)nonyl amide}

2-Chloroethylamine hydrochloride (11 g, $0.95 \mathrm{~mol}$ ) was placed in a round-bottom flask. nNonanoic acid chloride (11 g, $0.057 \mathrm{~mol})$ was dissolved in DCM $(150 \mathrm{ml})$ and added to the same flask. The mixture was cooled in an ice bath. Then, triethylamine $(30 \mathrm{ml}, 0.216 \mathrm{~mol})$ was added dropwise while stirring. The mixture was allowed to warm to room temperature and 
stirred overnight. The DCM was removed, and ethylacetate was added. The mixture was filtered to remove the triethylamine hydrochloride, and the filtrate was washed twice with $10 \%$ acetic acid solution, twice with saturated sodium bicarbonate, and twice with brine solution. The organic layer was dried over magnesium sulfate. Magnesium sulfate was filtered off, and the solvent was removed under reduced pressure, yielding the product as a white powder. Yield=9.9 g $(70 \%) ;{ }^{1} \mathrm{H}$ NMR $\left(300 \mathrm{MHz}, \mathrm{CDCl}_{3}\right) \delta 6.04$ (s (broad), -NH-CH $\left.2_{2}, 1 \mathrm{H}\right), 3.60$ (m, -NH-CH $2_{2}$ $\left.\mathrm{CH}_{2}-\mathrm{Cl}, 4 \mathrm{H}\right), 2.19\left(\mathrm{~m},-\mathrm{CH}_{2}-\mathrm{C}(\mathrm{O})-, 2 \mathrm{H}\right), 1.62\left(\mathrm{~m},-\mathrm{CH}_{2}-\mathrm{CH}_{2}-\mathrm{C}(\mathrm{O})-, 2 \mathrm{H}\right), 1.25\left(\mathrm{~m}, \mathrm{CH}_{3}\left(\mathrm{CH}_{2}\right)_{5-}\right.$ , $10 \mathrm{H}), 0.86\left(\mathrm{t}, \mathrm{J}=6.7 \mathrm{~Hz}, \mathrm{CH}_{3^{-}}, 3 \mathrm{H}\right)$.

\subsubsection{Synthesis of 2-(n-octyl)-2-oxazoline (OctOx)}

$\mathrm{N}$-(2-Chloroethyl)nonylamide $(9.9 \mathrm{~g}, 0.045 \mathrm{~mol})$ synthesized in the previous step was dissolved in dry THF (20 ml), and 18-crown-6-ether $(0.595 \mathrm{~g}, 0.00225 \mathrm{~mol})$ was added. The mixture was cooled in an ice bath and potassium hydroxide (7.56 g, $0.135 \mathrm{~mol}$ ) was added. The mixture was allowed to warm to room temperature and stirred overnight. THF was removed under reduced pressure, and the residue was dispersed in water and extracted 3 times with DCM. The organic layers were combined and dried with magnesium sulfate. After filtration and removing the solvent under reduced pressure, the resulting oil was dried with barium oxide and distilled under reduced pressure yielding the product as a clear colourless liquid. Yield=6.7 g (80 \%); $\mathrm{T}_{\text {boil }}=48$ ${ }^{\circ} \mathrm{C}\left(0,9\right.$ mbar); ${ }^{1} \mathrm{H}$ NMR $\left(300 \mathrm{MHz}, \mathrm{CDCl}_{3}\right) \delta 4.22\left(\mathrm{t}, \mathrm{C}-\mathrm{O}-\mathrm{CH}_{2}-\mathrm{CH}_{2}-\mathrm{N}=, 2 \mathrm{H}\right), 3.81(\mathrm{t},-\mathrm{C}-\mathrm{O}-$ $\left.\mathrm{CH}_{2}-\mathrm{CH}_{2}-\mathrm{N}=, 2 \mathrm{H}\right), 2.26\left(\mathrm{t},-\mathrm{CH}_{2}-\mathrm{C}(\mathrm{O}) \mathrm{N}-, 2 \mathrm{H}\right), 1.62\left(\mathrm{~m},-\mathrm{CH}_{2}-\mathrm{CH}_{2}-\mathrm{C}(\mathrm{O}) \mathrm{N}-, 2 \mathrm{H}\right), 1.26(\mathrm{~m}$, $\left.\mathrm{CH}_{3}\left(\mathrm{CH}_{2}\right)_{5^{-}}, 10 \mathrm{H}\right), 0.86\left(\mathrm{t}, \mathrm{J}=6.7 \mathrm{~Hz}, \mathrm{CH}_{3^{-}}, 3 \mathrm{H}\right)$.

\subsubsection{Synthesis of $1 \mathrm{H}, 1 \mathrm{H}, 2 \mathrm{H}, 2 \mathrm{H}-$ perfluorononanoic acid ${ }^{33}$}

The $1 \mathrm{H}, 1 \mathrm{H}, 2 \mathrm{H}, 2 \mathrm{H}$-perfluorooctyl iodide $(12 \mathrm{~g}, 6,2 \mathrm{~mL}, 0.025 \mathrm{~mol})$ was dissolved in $6 \mathrm{~mL}$ of diethyl ether and the first portion of this mixture (1-2 mL) was added to a suspension of $0.6 \mathrm{~g}$ $(0.025 \mathrm{~mol})$ magnesium in $100 \mathrm{~mL}$ of freshly distilled diethyl ether with the addition of a few crystals of iodine. The mixture was stirred at $37{ }^{\circ} \mathrm{C}$ until the reaction started (20-30 minutes). Subsequently, the rest of the solution of $1 \mathrm{H}, 1 \mathrm{H}, 2 \mathrm{H}, 2 \mathrm{H}$-perfluorooctyl iodide was added dropwise during 1.5-2 hours and then stirring was continued for another 3 hours. The mixture was cooled on an ice bath and then $15 \mathrm{~g}$ of dry ice were added slowly. The mixture was stirred for another 20 minutes before $25 \mathrm{~mL}$ of $20 \% \mathrm{H}_{2} \mathrm{SO}_{4}$ was added. The organic layer was separated, washed with saturated $\mathrm{NaCl}$ solution and dried over magnesium sulfate. The solvent was removed under reduced pressure and the residue was recrystallized from DCM. The 
resulting white crystals also contained the side product of iodide dimerization $1,1,1,2,2,3,3,4,4,5,5,6,6,11,11,12,12,13,13,14,14,15,15,16,16,16$-hexacosafluorohexadecane.

\subsubsection{Purification of $1 \mathrm{H}, 1 \mathrm{H}, 2 \mathrm{H}, 2 \mathrm{H}$-perfluorononanoic acid}

The obtained acid (colorless crystals) was dispersed in concentrated $\mathrm{NaOH}$ solution and stirred under heating. The precipitate was separated by decantation, the solution was neutralized by addition of $20 \% \mathrm{H}_{2} \mathrm{SO}_{4}$ and extracted 3 times with diethyl ether. The organic layers were combined, washed with saturated $\mathrm{NaCl}$ solution and dried over $\mathrm{MgSO}_{4}$. The solvent was removed in vacuum yielding the pure product as white crystals. Yield $=5 \mathrm{~g}(50 \%) .{ }^{1} \mathrm{H}$ NMR $\left(300 \mathrm{MHz}, \mathrm{CDCl}_{3}\right) \delta 9.17$ (s (wide), $\left.-\mathrm{COOH}, 1 \mathrm{H}\right), 2.71\left(\mathrm{t},-\mathrm{CH}_{2}-\mathrm{COOH}, 2 \mathrm{H}\right), 2.48$ (m, - $\mathrm{CF}_{2}-$ $\left.\mathrm{CH}_{2-}, 2 \mathrm{H}\right)$.

\subsubsection{Synthesis of $1 \mathrm{H}, 1 \mathrm{H}, 2 \mathrm{H}, 2 \mathrm{H}-$ perfluorononanoic acid chloride}

The acid synthesized in the previous step ( $5 \mathrm{~g}, 0.013 \mathrm{~mol}$ ) was mixed with thionyl chloride 2.83 $\mathrm{mL}$ (4.64 $\mathrm{g}, 0.039 \mathrm{~mol})$ and few drops of pyridine were added as a catalyst. The mixture was stirred at $50{ }^{\circ} \mathrm{C}$ overnight. The excess of thionyl chloride was removed under reduced pressure and the residue was distilled under reduced pressure. The product was used in the next reaction without further purification. Yield $=5 \mathrm{~g}(94 \%) .{ }^{1} \mathrm{H}$ NMR $\left(300 \mathrm{MHz}, \mathrm{CDCl}_{3}\right) \delta 3.24\left(\mathrm{t},-\mathrm{CH}_{2}-\right.$ $\mathrm{C}(\mathrm{O}) \mathrm{Cl}, 2 \mathrm{H}), 2.53\left(\mathrm{~m},-\mathrm{CF}_{2}-\mathrm{CH}_{2-}, 2 \mathrm{H}\right)$.

\subsubsection{Synthesis of 2-(1H,1H,2H,2H-perfluorooctyl)-2-oxazoline $\left(\mathrm{R}_{\mathrm{f}}^{6} \mathrm{EtOx}\right)$}

2-Bromoethylamine hydrobromide (4.92 g, $0.024 \mathrm{~mol}$ ) was dispersed in $50 \mathrm{~mL}$ of DCM, Then, $5 \mathrm{~mL}$ of triethylamine $(3.64 \mathrm{~g}, 0.036 \mathrm{~mol})$ was added and the mixture was stirred for $15-20$ minutes. The reaction mixture was cooled on an ice/ $\mathrm{NaCl}$ bath. $1 \mathrm{H}, 1 \mathrm{H}, 2 \mathrm{H}, 2 \mathrm{H}-$ Perfluorononanoic acid chloride $(5 \mathrm{~g}, 0.012 \mathrm{~mol}$ ) was mixed with the same volume of DCM and added drop-wise under stirring and cooling. The mixture was allowed to warm to room temperature and stirred over 2 days. The solution was washed twice with water and saturated $\mathrm{NaCl}$ solution and dryed over $\mathrm{MgSO}_{4}$. The solvent was removed under reduced pressure and the oily residue was distilled over $\mathrm{BaO}$ yielding the product as a colorless liquid. Yield $=4.5 \mathrm{~g}$

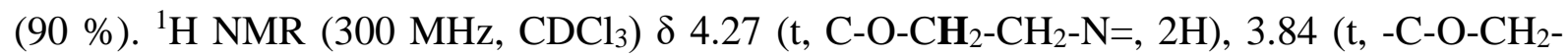
$\left.\mathrm{CH}_{2}-\mathrm{N}=, 2 \mathrm{H}\right), 2.63-2.37\left(\mathrm{~m}, \mathrm{C}_{6} \mathrm{~F}_{13}-\mathrm{CH}_{2}-\mathrm{CH}_{2-}, 4 \mathrm{H}\right)$. 


\subsection{Polymer synthesis}

The synthesis of all polymers was performed in a pressure reactor (Ace pressure tube, Ace Glass, Inc.) under argon atmosphere using freshly distilled and dried monomers and solvents. The general procedure was as follows:

$\mathrm{R}_{\mathrm{f}}^{6} \mathrm{EtOx}\left(0.3 \mathrm{~g}, 7.2^{*} 10^{-4} \mathrm{~mol}\right)$ was dissolved in acetonitrile $(3.2 \mathrm{ml})$, and methyl tosylate $(0.0134$ $\mathrm{g}, 7.2^{*} 10^{-5} \mathrm{~mol}$ ) was added as the initiator. The mixture was stirred for 22 minutes at $140{ }^{\circ} \mathrm{C}$ in a pressure reactor. After cooling to room temperature, the second monomer - 2-(n-octyl)-2oxazoline $\left(0.264 \mathrm{~g}, 14.4 * 10^{-4} \mathrm{~mol}\right)$ - was added, and the mixture was stirred again for 31 minutes at $140{ }^{\circ} \mathrm{C}$. Next, 2-methyl-2-oxazoline $(0.612 \mathrm{~g}, 0.072 \mathrm{~mol})$ was added and the polymerization mixture was stirred for 27 minutes at $140{ }^{\circ} \mathrm{C}$. The mixture was cooled to room temperature and the polymerization was quenched by the addition of $0.3 \mathrm{~mL}$ of $1 \mathrm{M} \mathrm{KOH}$ $\left(0.0168 \mathrm{~g}, 3^{*} 10^{-4} \mathrm{~mol}\right)$ solution in $\mathrm{MeOH}$ and stirred overnight. The polymer was isolated by precipitation in cold diethyl ether yielding the triblock copolymer as a white powder.

\subsection{Methods}

\subsubsection{Dynamic Light Scattering (DLS)}

Dynamic Light Scattering (DLS) was performed to characterize the copolymers in dilute solutions. For this purpose, the hydrodynamic diameter of the particles, $D_{h}$, and the scattering intensity were measured at a scattering angle of $\theta=173^{\circ}$ with a Zetasizer Nano-ZS instrument, model ZEN3600 (Malvern Instruments, UK). The DTS (Nano) program was used to evaluate the data. The intensity-weighted value of the apparent $D_{h}$ and Polydispersity Index PDI were chosen to characterize the dispersity of the solutions. For clarity, distribution functions were normalized by the amplitude of the peak of the highest intensity.

All solutions were prepared via the direct dissolution of the copolymers in water or dimethylsulphoxide as well as via a solvent exchange method (for aqueous solutions only) in which the polymer was molecularly dissolved in methanol and self-assembly was induced by dialysis against water. ${ }^{34,35}$

\subsubsection{Size Exclusion Chromatography - Multi-Angle Light Scattering (SEC-MALS)}

Labio Biospher GMB100 $7.5 \mathrm{~mm}$ x $300 \mathrm{~mm}$, particle size $10 \mu \mathrm{m}$, size exclusion column, applicable in aqueous as well as in organic mobile phases, was used for the analysis of the poly(2-oxazoline)s using methanol as the mobile phase at $0.18 \mathrm{ml} / \mathrm{min}$. The pump was a 
Shimadzu 20ADvp liquid chromatography pump (Shimadzu Corp, Kyoto, Japan). The vacuum degasser was a DeltaChrom TVD (Watrex, Prague, Czech Republic). The $40 \mathrm{mg} / \mathrm{ml}$ polymer solutions in methanol were injected manually using a six port PEEK injection valve equipped with a $50 \mu 1$ sample loop (Upchurch Scientific, Oak Harbor, WA). A home made in-line $25 \mathrm{~mm}$ filter holder with a $0.02 \mu \mathrm{m}$ Anodisc 25 membrane (Whatman, Maidstone, UK) was positioned between the pump and the injection valve.

The light scattering detector was a DAWN-DSP multi-angle light scattering instrument (Wyatt Technology, Santa Barbara, CA) and a Shodex RI-101 differential refractometer (Showa Denko, Japan) served as the concentration detector. The signals from the detectors were collected and analysed using ASTRA for Windows 4.50 software (Wyatt Technology, Santa Barbara, CA). The angular dependence of the scattered light intensity was found to be negligible for all samples.

The refractive index increment of the poly(2-oxazoline)s in methanol was determined using a Brookhaven BI-DNDC differential refractometer and BI-DNDCW software.

It should be noted here that this two detector arrangement with both a DAWN-DSP light scattering unit as an absolute molecular weight detector and single RI detection SEC units does not require the use of polymer standards to determine the polymer molar mass and dispersity $(\bigoplus)$.

\subsubsection{Transmission Cryo-Electron Microscopy (Cryo-TEM)}

Specimens were prepared in a controlled environment vitrification system (CEVS) at $25^{\circ} \mathrm{C}$ and $100 \%$ relative humidity. A drop (about $3 \mu \mathrm{L}$ ) of the sample was pipetted onto a perforated carbon film-coated electron microscopy copper grid, blotted with filter paper, and plunged into liquid ethane at its freezing point. Such specimens were then transferred to a Gatan 626 cryoholder and imaged at an acceleration voltage $200 \mathrm{kV}$ in an FEI (Eindhoven, NL) Talos 200C high-resolution transmission electron microscope at about $-175^{\circ} \mathrm{C}$, in the low-dose imaging mode to minimize electron-beam radiation-damage. Image contrast was enhanced by "phaseplates" of the Talos. Images were digitally recorded with an FEI I Falcon II direct-imaging 16megapixel camera. 


\subsection{4. ${ }^{19}$ F Nuclear Magnetic Resonance (NMR) Spectroscopy}

The ${ }^{19} \mathrm{~F}$ NMR spectra were measured at $11.7 \mathrm{~T}$ on a Bruker Avance III HD 500 US/WB NMR spectrometer (Karlsruhe, Germany, 2013) using a solid-state 4-mm CP/MAS probehead optimized for the measurement of ${ }^{19} \mathrm{~F}$ nuclei. The Hahn-echo experiment was applied to suppress the probehead residual signal; the echo-delay was $10 \mathrm{~ms}$; the duration of the $90^{\circ}(19 \mathrm{~F})$ pulse was $1.5 \mu \mathrm{s}$; the repetition delay was $2 \mathrm{~s}$; and 512-1024 scans were accumulated for each spectrum. ${ }^{19}$ F NMR chemical shift scale was calibrated using PTFE for which the signal was set to $-122 \mathrm{ppm}$. Chloroform was used as the solvent.

2.4.5. Small-Angle Neutron Scattering (SANS) experiments were performed at FRM II, Garching, Germany on the KWS-2 instrument. ${ }^{36}$ Measurements were made on a 128 x $128{ }^{3} \mathrm{He}$ tubes array detector (pixel size $8 \mathrm{~mm}$ ) using a non-polarized, monochromatic (wavelength $\lambda$ set by a velocity selector) incident neutron beam collimated with rectangular apertures for two sample-to-detector distances, namely 2,8 , and $20 \mathrm{~m}(\lambda=0.6 \mathrm{~nm})$. With this setup, the investigated $q$-range was $0.015 \mathrm{~nm}^{-1}$ to $4.6 \mathrm{~nm}^{-1}$. In all cases, the two-dimensional scattering patterns were isotropic and were azimuthally averaged, resulting in the dependence of the scattered intensity $I_{s}(q)$ on the momentum transfer $q=4 \pi \sin \theta / \lambda$, where $2 \theta$ is the scattering angle. The curves were corrected for background scattering from the empty cell and for detector efficiency. Helma quartz cells 1 and $2 \mathrm{~mm}$ thick were used for experiments. SANS Experiments were performed in $\mathrm{D}_{2} \mathrm{O}$ and DMSO-d6. The buffer was measured and proper subtracted.

\subsubsection{SANS data fitting}

The scattered intensity curves were fitted using the sphere with attached Gaussian chain model implemented in SASFit software. ${ }^{37}$

The scattering curves in $\mathrm{D}_{2} \mathrm{O}$ and partially in DMSO-d6 were fitted using the following function:

$$
I(q)=P_{s g c}(q)+P_{a g g}(q)
$$

The overall scattering intensity of the sphere with attached Gaussian chain written as:

$$
\begin{gathered}
P_{\text {sgc }}=N_{\text {agg }}^{2} \beta_{\text {core }}^{2} P_{\text {core }}(q)+N_{\text {agg }} \beta_{\text {brush }}^{2} P_{\text {brush }}(q)+2 N_{\text {agg }}^{2} \beta_{\text {core }} \beta_{\text {brush }} S_{\text {brush-core }}(q)+ \\
N_{\text {agg }}\left(N_{\text {agg }}-1\right) \beta_{\text {brush }}^{2} S_{\text {brush-brush }}(q),
\end{gathered}
$$


where $N_{a g g}^{2} \beta_{\text {core }}^{2} P_{\text {core }}(q)$ is self-correlation term of the core, $N_{a g g} \beta_{b r u s h}^{2} P_{b r u s h}(q)$ is selfcorrelation term of the chains, $2 N_{a g g}^{2} \beta_{\text {core }} \beta_{\text {brush }} S_{\text {brush-core }}(q)$ is the cross-term between the core and chains and $N_{a g g}\left(N_{a g g}-1\right) \beta_{\text {brush }}^{2} S_{\text {brush-brush }}(q)$ is the cross-term between different chains. $N_{a g g}$ is the aggregation number of polymers forming the nanoparticle per surface area, $\beta_{\text {brush }}=V_{\text {brush }}\left(\eta_{\text {brush }}-\eta_{\text {solv }}\right)$ and $\beta_{\text {core }}=V_{\text {core }}\left(\eta_{\text {core }}-\eta_{\text {solv }}\right)$ are the excess scattering lengths of a block in the corona and in the core, respectively. $V_{\text {brush }}$ and $V_{\text {core }}$ are the total volume of a block in the corona and in the core, respectively. $\eta_{\text {brush }}$ and $\eta_{\text {core }}$ are the corresponding SLDs. $P_{\text {core }}(q)$ is scattering of spherical core

$$
P_{\text {core }}(q, R)=\frac{(\sin (q R)-q R \cos (q R))}{(q R)^{3}}
$$

The scattering intensity for the brush of is given by:

$$
P_{\text {brush }}\left(q, R_{g}\right)=2 \frac{\exp (-x)-1+x}{x^{2}}, \quad \text { where } x=R_{g}^{2} q^{2}
$$

The modified Porod function was used to describe the contribution of large aggregates $\left(P_{\text {agg }}\right)$ at the lowest $q$ range: $C_{0}+\frac{c_{1}}{q^{\alpha}}$, where $\alpha$ is modified Porod exponent.

Excess scattering lengths of polymeric shell and a core were fixed during the fitting procedure.

The scattering curves from diblock copolymers in DMSO-d6 were fitted using the following function:

$$
I(q)=P_{g g c}(q)+P_{a g g}(q)
$$

where $P_{\text {ggc }}$ describes the form factor of Generalized Gaussian coil:

$$
P_{g g c}(q)=I_{0}^{c} \frac{U^{\frac{1}{2 v}} \Gamma\left(\frac{1}{2 v}\right)-\Gamma\left(\frac{1}{v}\right)-U^{\frac{1}{2 v}} \Gamma\left(\frac{1}{2 v}, U\right)+\Gamma\left(\frac{1}{v}, U\right)}{v U^{1 / v}}
$$

here, $U=(2 v+1)(2 v+2) \frac{q^{2} R_{g}^{2}}{6}$, and $\Gamma\left(\frac{1}{2 v}\right)-$ Gamma function. 


\section{RESULTS AND DISCUSSIONS}

\subsection{Monomer synthesis}

The synthesis of the hydrophobic 2-octyl-2-oxazoline monomer was performed as described in our previous work. ${ }^{29}$ Subsequently, several pathways were tested for the synthesis of the 2$1 \mathrm{H}, 1 \mathrm{H}, 2 \mathrm{H}, 2 \mathrm{H}-$ perfluorooctyl-2-oxazoline fluorophilic monomer. This monomer was chosen to have a strong fluorophilic character while the ethyl spacer ensures similar reactivity compared to 2-alkyl-2-oxazolines as we previously determined for 2-trifluoromethylethyl-2-oxazoline. ${ }^{32}$

As the perfluoroalkyl chain length is extended compared to previous reports by Jordan, ${ }^{25}$ the solubility is significantly reduced in common organic solvents complicating its synthesis. Nonetheless, we first attempted to form the $1 \mathrm{H}, 1 \mathrm{H}, 2 \mathrm{H}, 2 \mathrm{H}$-perfluorooctylcyanide by reaction of the $1 \mathrm{H}, 1 \mathrm{H}, 2 \mathrm{H}, 2 \mathrm{H}$-perfluorooctyliodide with sodium cyanide, in analogy to the report of Jordan $^{25}$ for the preparation of the 2- $(1 \mathrm{H}, 1 \mathrm{H}, 2 \mathrm{H}, 2 \mathrm{H}$-perfluorohexyl)-2-oxazoline via the WitteSeeliger synthesis of 2-oxazolines from nitriles (Scheme 1). ${ }^{38}$ Unfortunately, the corresponding nitrile was not obtained under the described conditions in the case of $1 \mathrm{H}, 1 \mathrm{H}, 2 \mathrm{H}, 2 \mathrm{H}-$ perfluorooctyl iodide, probably because of the lower solubility of the iodide.

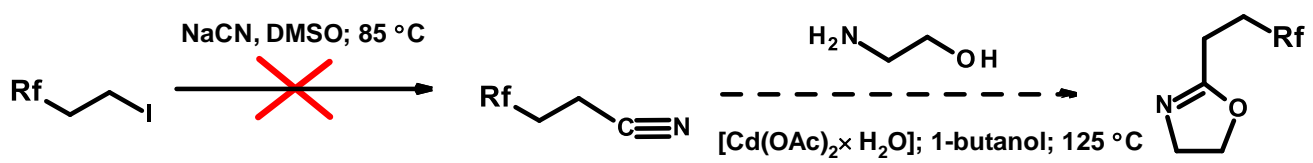

Scheme 1. Attempted Witte-Seeliger synthesis of 2-(1H,1H,2H,2H-perfluorohexyl)-2oxazoline.

Subsequently, we attempted the $\alpha$-deprotonation of 2-methyl-2-oxazoline ( $\mathrm{MeOx}$ ) followed by a substitution reaction with an alkylbromide/iodide. ${ }^{39,40}$ More specifically, MeOx was deprotonated using n-butyllithium/tetramethylethylenediamine ${ }^{41}$ and the obtained carbanion was then reacted with $1 \mathrm{H}, 1 \mathrm{H}, 2 \mathrm{H}, 2 \mathrm{H}$-perfluorooctylbromide to form $2-(1 \mathrm{H}, 1 \mathrm{H}, 2 \mathrm{H}, 2 \mathrm{H}, 3 \mathrm{H}, 3 \mathrm{H}-$ perfluorononyl)-2-oxazoline (Scheme 2). Unfortunately, the attempt to apply this procedure for the synthesis of fluorinated 2-oxazolines failed and the usage of perfluorooctyl iodide was unsuccessful too. 


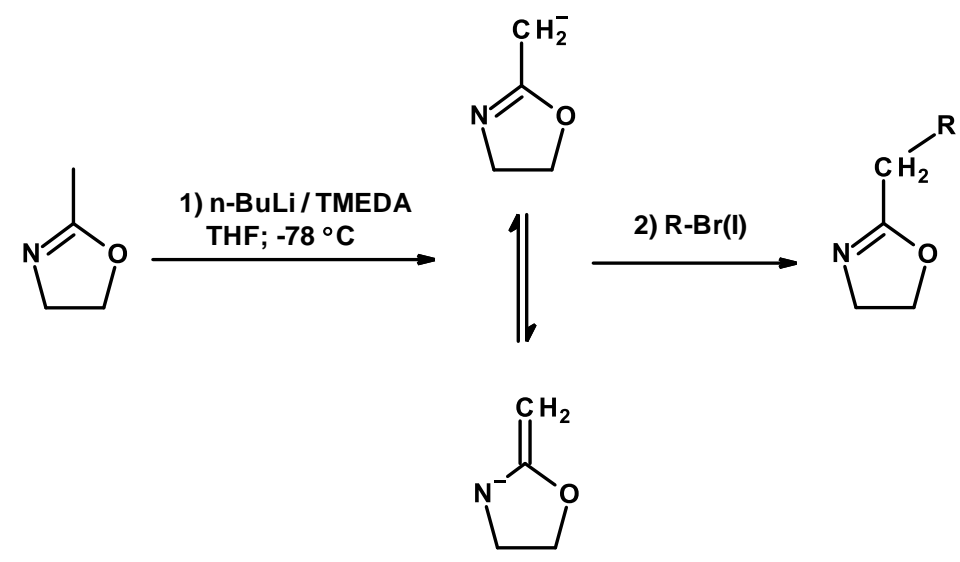

Scheme 2. Functionalization of 2-oxazolines by $\alpha$-deprotonation of 2-methyl-2-oxazoline and imine-enamine equilibrium of the intermediate anion.

Our failure can be explained as follows. The intermediate anion exists in the form of imineenamine equilibrium (Scheme 2, middle). In case of soft leaving groups (according to hard and soft Lewis acid and base theory), such as bromide or iodide, the substitution reaction via the $\alpha$ position (imine form) is preferred. At the same time, the fluorine can act as a hard leaving group and the enamine form will be more active, potentially leading addition onto the nitrogen rather than the side chain. The ${ }^{1} \mathrm{H}$ NMR spectra indicated the presence of an enamine in the reaction product as the signals from the protons at the double bond were observed at 5.64 and $5.75 \mathrm{ppm}$. Alternatively, the failure may be (partially) due to elimination of $\mathrm{HBr}$ from the fluorinated reactant in presence of a strong base. Thus, it could be concluded that this method is not applicable for functionalization of 2-oxazolines by fluorine containing alkyl bromides/iodides.

In our third and successful attempt, we adopted the Wenker method for the synthesis of 2oxazolines from $\beta$-halo amides, ${ }^{42}$ supplemented by the synthesis of $1 \mathrm{H}, 1 \mathrm{H}, 2 \mathrm{H}, 2 \mathrm{H}$ perfluorononanoic acid via Grignard reaction as previously reported by Baker et al. ${ }^{33}$ The required carboxylic acid with the ethyl spacer was synthesized starting from $1 \mathrm{H}, 1 \mathrm{H}, 2 \mathrm{H}, 2 \mathrm{H}-$ perfluorooctyl iodide and magnesium in presence of iodine. The obtained Grignard reagent was then treated with dry ice yielding the target carboxylic acid, together with some unwanted iodide dimerization product (Scheme 3). The total yield of the desired acid was 40-50\%, which is in agreement with literature data. ${ }^{33}$ The use of $1 \mathrm{H}, 1 \mathrm{H}, 2 \mathrm{H}, 2 \mathrm{H}$-perfluorooctyl bromide decreased the amount of dimer formation and also increased the yield of the acid (up to $60 \%$ ). 


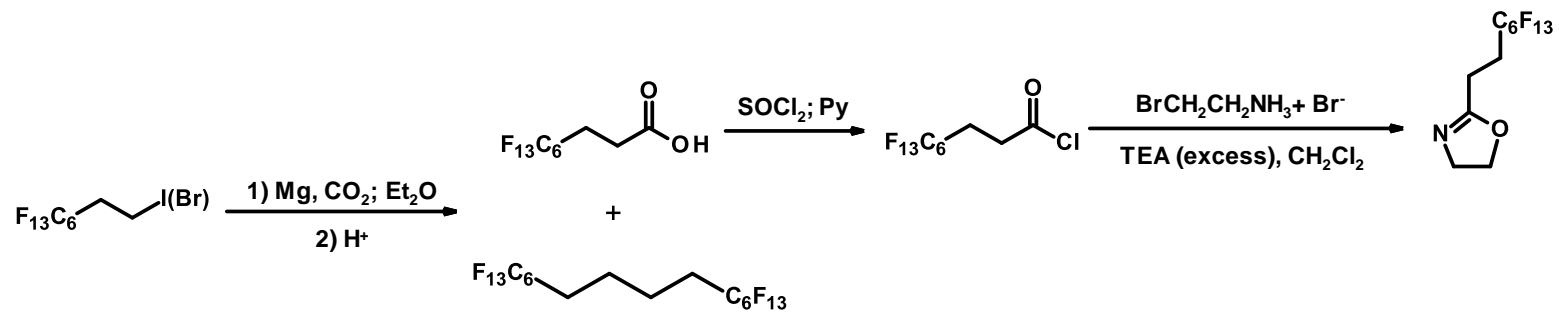

Scheme 3. Successful synthesis of 2-(1H,1H,2H,2H-perfluorooctyl)-2-oxazoline ( $\left.\mathrm{R}_{\mathrm{f}}{ }^{6} \mathrm{EtOx}\right)$ via the Wenker method.

Subsequently, the obtained $1 \mathrm{H}, 1 \mathrm{H}, 2 \mathrm{H}, 2 \mathrm{H}$-perfluorooctyl carboxylic acid was converted to the acid chloride by the reaction with thionyl chloride, followed by reaction with 2bromoethylamine hydrobromide in the presence of excess trimethylamine inducing in situ ringclosure of the formed amidoethylbromide to the 2-oxazoline ring. The $\mathrm{R}_{\mathrm{f}}{ }^{6} \mathrm{EtOx}$ was isolated by distillation with a total yield up to $50 \%$ which is higher than the one described by Jordan et al.. ${ }^{25}$ We conclude that the Grignard reaction based procedure could be used as an alternative way for the synthesis of fluorine containing 2-oxazolines.

The polymerization kinetics of $\mathrm{R}_{\mathrm{f}}{ }^{6} \mathrm{EtOx}$ was studied according to the standard procedure, being polymerization at $140{ }^{\circ} \mathrm{C}$ in acetonitrile with methyl tosylate (MeOTs) as initiator. ${ }^{43}$ The conversion of the monomer was followed by gas chromatography, which is plotted in a first order kinetic plot in Figure 1. The $\mathrm{R}_{\mathrm{f}}{ }^{6}$ EtOx monomer shows linear first order kinetics, which is typical for living CROP. The $k_{\mathrm{p}}$ value calculated from the slope is $143 * 10^{-3} \mathrm{~L}^{*} \mathrm{~mol}^{-1} * \mathrm{~s}^{-1}$, which is very similar to the $k_{p}$ of 2-methyl-2-oxazoline $\left(146^{*} 10^{-3} \mathrm{~L}^{*} \mathrm{~mol}^{-1 *} \mathrm{~s}^{-1}\right) .{ }^{44}$ Also, the similarity of the $k_{\mathrm{p}}$ for $\mathrm{R}_{\mathrm{f}}{ }^{6} \mathrm{EtOx}$ and for obtained earlier 2-(3,3,3-trifluoropropyl)-2-oxazoline $\left(\mathrm{CF}_{3} \mathrm{EtOx}\right.$, $\left.k_{\mathrm{p}}=129 * 10^{-3} \mathrm{~L}^{*} \mathrm{~mol}^{-1} \mathrm{~s}^{-1}\right)^{32}$ demonstrates that the length of the perfluoroalkyl substituent in 2oxazolines with a double methylene spacer do not affect the $k_{\mathrm{p}}$ value. Even at low DP, poly-2$\left(1 \mathrm{H}, 1 \mathrm{H}, 2 \mathrm{H}, 2 \mathrm{H}\right.$-perfluorooctyl)-2-oxazolines (polyR $\left.{ }_{\mathrm{f}}^{6} \mathrm{EtOx}\right)$ was found to be insoluble at room temperature, thereby obstructing the analysis of its $\mathrm{M}_{n}$ and dispersity. 


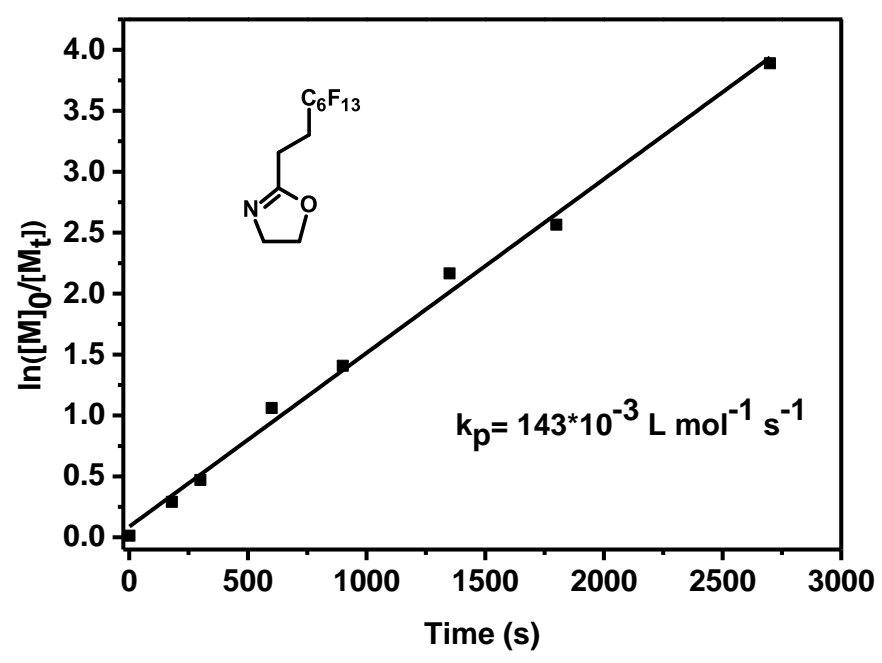

Figure 1. First order kinetic plot for the cationic ring-opening polymerization of $\mathrm{R}_{\mathrm{f}}{ }^{6} \mathrm{EtOx}$ (solvent - acetonitrile; monomer concentration - $1 \mathrm{M}$; initiator - p-methyltoluenesulfonate (MeOTos); temperature $-140^{\circ} \mathrm{C}$; targeted $\mathrm{DP}-100$ ).

\subsection{Block Copolymer synthesis}

Having obtained the fluorinated monomer, we performed the synthesis of amphiphilic di- and triblock copolymers. 2-Methyl-2-oxazoline was used for the synthesis of the hydrophilic block and 2-n-octyl-2-oxazoline (OctOx) was chosen for the hydrophobic block as nonfluorinated analogue of $\mathrm{R}_{\mathrm{f}}^{6} \mathrm{EtOx}$ (Figure 2). It was also proposed that combination of long fluorinated and non-fluorinated fragments will promote the formation of multicompartment micelles in solution.

\section{Hydrophilic Fluorophilic}

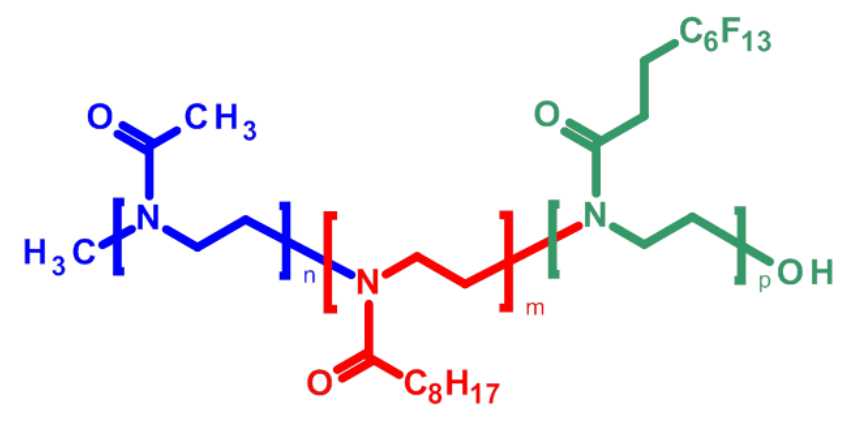

\section{Lipophilic}

Figure 2. The common structure of investigated fluorophilic-lipophilic-hydrophilic copoly(2oxazoline)s. 
All polymers were synthesized via CROP in acetonitrile using MeOTos as the initiator. The monomers were polymerized subsequently, whereby the next monomer was added after a full conversion of the previous one. The full conversion time was calculated by following formula:

$$
t=\ln \left(\frac{[M]_{0}}{[M]_{\mathrm{t}}}\right) /\left(k_{\mathrm{p}} *[I]_{0}\right)
$$

using literature data ${ }^{44}$ and the previously discussed kinetic study of $\mathrm{R}_{\mathrm{f}}{ }^{6} \mathrm{EtOx}$ monomer. Here, $[M]_{0}$ and $[M]_{t}$ are monomer concentrations at the initial time and $\mathrm{t}$ stands for reaction time, respectively, $k_{p}$ is the polymerization rate constant and $[I]_{0}$ the initial concentration of the initiator. ${ }^{44}$ The time to reach a value of 4 for $\ln \left([M]_{d} /[M]_{t}\right)$ was calculated corresponding to 98 $\%$ conversion of the monomer.

To ensure the water solubility of the resulting copolymers, a high molar ratio of the hydrophilic block was taken. Despite this, the wt. \% of fluorophilic block in the copolymers is quite high due to high molecular weight of fluorophilic monomer of $417 \mathrm{~g} / \mathrm{mol}$. With increasing of the fluorinated block length, the copolymers become insoluble even in methanol (e.g. polymers PD and PF in Table 1), which may be attributed to the high crystallization tendency of fluoroalkyl chains.

All polymers were characterized by SEC-MALS and ${ }^{1} \mathrm{H}$ NMR spectroscopy, and the results are presented in Table 1.

Table 1. Characteristics of the synthesized block copoly(2-oxazoline)s.

\begin{tabular}{|c|c|c|c|c|c|}
\hline & \multirow{2}{*}{ Composition (NMR) } & \multirow{2}{*}{$\begin{array}{c}\mathrm{M}_{\mathrm{n}}, \\
\mathrm{g} / \mathrm{mol} \\
(\mathrm{SEC}- \\
\text { MALS) }\end{array}$} & \multirow{2}{*}{$\begin{array}{l}Ð \text { (SEC- } \\
\text { MALS) }\end{array}$} & \multicolumn{2}{|c|}{ Block ratios } \\
\hline & & & & mol. \% & wt. \% \\
\hline P1 & $\mathrm{MeOx}_{55}-\mathrm{R}_{\mathrm{f}}^{6} \mathrm{EtOx}_{6}$ & 7200 & 1.36 & $91: 9$ & $65: 35$ \\
\hline $\mathrm{P} 2$ & $\mathrm{MeO}_{43}-\mathrm{R}_{\mathrm{f}}{ }^{6} \mathrm{EtOx}_{5}$ & 5700 & 1.34 & $89: 11$ & $63: 37$ \\
\hline P3 & $\mathrm{MeOx}_{38}-\mathrm{R}_{\mathrm{f}}{ }^{6} \mathrm{EtO} \mathrm{x}_{5}$ & 5400 & 1.28 & $88: 12$ & $60: 40$ \\
\hline PD & $\mathrm{MeOx}_{60}-\mathrm{R}_{\mathrm{f}}{ }^{6} \mathrm{EtOx}_{10} *$ & - & - & $85: 15$ & $55: 45$ \\
\hline PF & $\mathrm{MeO}_{40}-\mathrm{R}_{\mathrm{f}}{ }^{6} \mathrm{EtOx}_{10} *$ & - & - & $80: 20$ & $45: 55$ \\
\hline
\end{tabular}




\begin{tabular}{c|c|c|c|c|c}
\hline $\mathrm{P} 4$ & $\mathrm{MeOx}_{45}-\mathrm{OctO}_{4}-\mathrm{R}_{\mathrm{f}}{ }^{6} \mathrm{EtOx}_{4}$ & 6200 & 1.35 & $86: 7: 7$ & $61: 12: 27$ \\
$\mathrm{P5}$ & OctOx$_{7-\mathrm{MeOx}_{41}-\mathrm{R}_{\mathrm{f}}{ }^{6} \mathrm{EtOx}_{4}}$ & 6400 & 1.4 & $13: 79: 8$ & $20: 55: 25$ \\
$\mathrm{P6}$ & $\mathrm{MeOx}_{55}-\mathrm{OctO}_{5}-\mathrm{R}_{\mathrm{f}}{ }^{6} \mathrm{EtOx}_{4}$ & 7300 & 1.23 & $86: 8: 6$ & $65: 12: 23$
\end{tabular}

*The proposed block ratios in polymers $P D$ and $P F$ was calculated from the initial monomer ratio.

\subsection{Self-assembly study}

The copolymers P1-P6 were found to be molecularly dissolved in several solvents including methanol, ethanol, chloroform, similarly to our previous studies on fluorinated poly(2oxazoline)s. ${ }^{29,32}$

The aqueous solutions of the copolymers were prepared using two procedures. In the first case the polymers were first dissolved in methanol and then dialyzed against water. The alternative procedure was direct dissolution of the copolymers in water.

According to the DLS results, the solutions of diblock copolymers that were prepared by dialysis contained mainly small particles with a hydrodynamic diameter $D_{\mathrm{h}}$ of 20-40 nm and a minor fraction of larger aggregates (See Supporting Information Figure S3).

The preparation method has some impact on the fraction of large aggregates. The distribution functions for all diblock copolymers obtained by direct dissolution have a higher content of particles with mean $D_{h}$ value of 150-300 $\mathrm{nm}$. To gain deeper insights on each fraction that was observed in the DLS study, cryo-TEM experiments were conducted. The cryo-TEM images of the P2 copolymer in water shows that polymersomes are formed in both cases, whereby their diameter depends on the preparation method (Figure $3 \mathrm{~A}$ and B). 

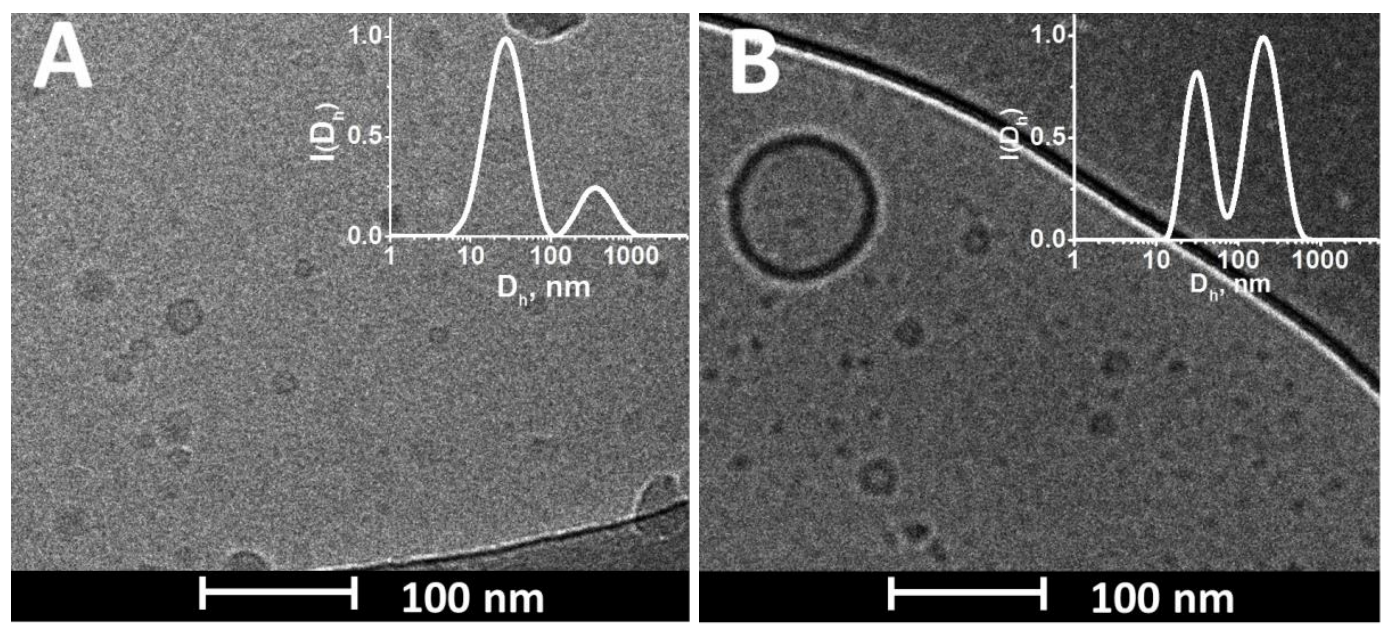

Figure 3. Cryo-TEM images of polymersomes in aqueous solutions of P2 (A - solvent exchange method, B - direct dissolution). The insets are DLS distribution functions of $D_{\mathrm{h}}$ for respective aqueous solutions.

The distribution functions for all three triblock copolymers in water obtained by solvent exchange show one peak of an approximately similar $D_{h}$ value of $30 \mathrm{~nm}$. The Cryo-TEM study of P4 and P5 revealed the presence of solid spheres with diameter about $20 \mathrm{~nm}$ that can be attributed to spherical micelles (Figure 4). At the same time, the presence of polymersomes in aqueous solution of triblock copolymers was not observed. It could be explained by the immiscibility of lipophilic and fluorophilic blocks, which makes the formation of complex hydrophobic polymersome layer (lipophilic-fluorophilic-lipophilic) thermodynamically unfavorable at a given blocks length. Similar effect was observed earlier for MeOx-b-OctOx copolymers with terminal perfluoroalkyl chains. ${ }^{29}$
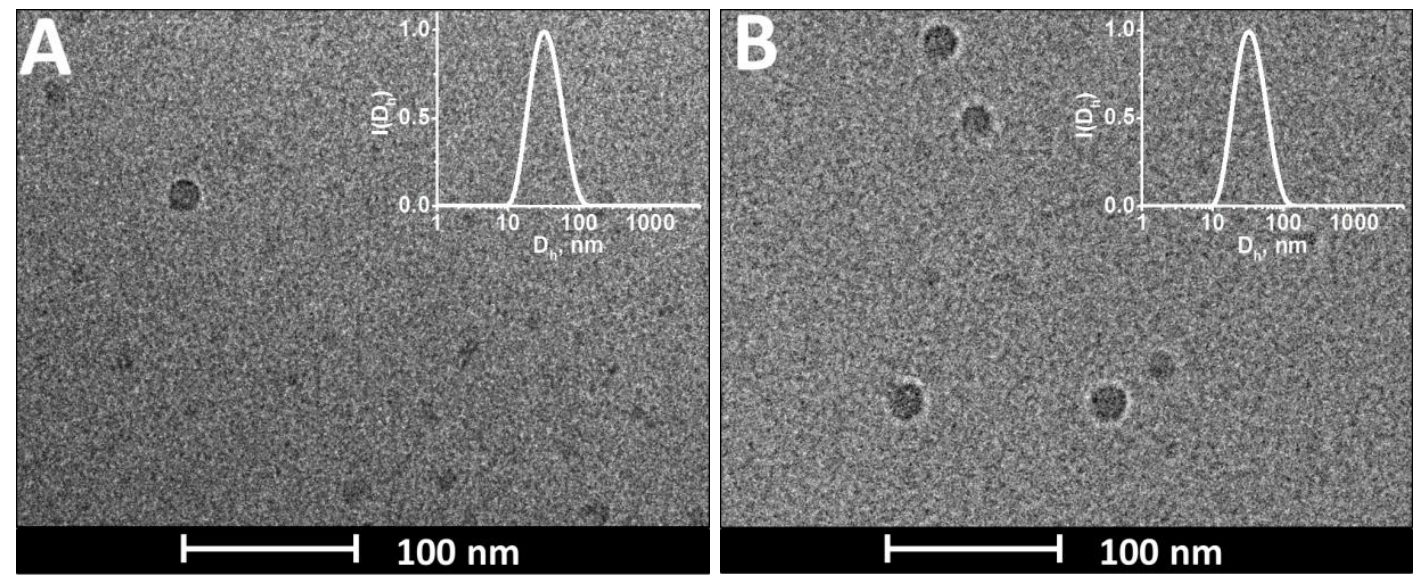
Figure 4. Cryo-TEM images of spherical micelles formed by triblock copolymers P4 (A) and P5 (B) in aqueous solutions (solvent exchange). The insets are DLS distribution functions of $D_{\mathrm{h}}$ for respective aqueous solutions.

Although the obtained copolymers are molecularly soluble in a number of solvents, their selfassembly in non-aqueous solvents could be expected as well. It is known that polymers solubility is affected by many factors and it is essential to use a parameter that takes into account the contribution of different origin. For that reason the Hansen solubility parameters were chosen. The total of Hansen solubility parameter $\delta_{\text {total }}$ consists of three components:

$$
\delta_{\text {total }}=\sqrt{\delta_{\mathrm{d}}^{2}+\delta_{\mathrm{p}}^{2}+\delta_{\mathrm{h}}^{2}}
$$

where $\delta_{\mathrm{d}}, \delta_{\mathrm{p}}$ and $\delta_{\mathrm{h}}$ are components related to dispersion interactions, polarity and hydrogen bonding, respectively. ${ }^{45}$ The Table 2 represents the literature data ${ }^{45}$ on Hansen parameters for the solvents used in our study and the solution behavior of obtained copolymers. One can see that water has the highest value of $\delta_{\mathrm{p}}$ and it could be hypothesized that self-assembly could be observed in solvent with polarity comparable to water.

Table 2. The solution behavior of di- and triblock copolymers (determined by DLS) and Hansen solubility parameters of respective solvents.

\begin{tabular}{|l|c|c|c|c|c|}
\hline \multirow{2}{*}{ Solvent } & \multicolumn{4}{|c|}{ Hansen solubility parameters } & \multirow{2}{*}{ Behavior } \\
\cline { 2 - 5 } Diethyl ether & $\boldsymbol{\delta}_{\text {total }}$ & $\boldsymbol{\delta}_{\mathbf{d}}$ & $\boldsymbol{\delta}_{\mathbf{p}}$ & $\boldsymbol{\delta}_{\mathbf{h}}$ & Insoluble \\
\hline Chloroform & 15.40 & 14.50 & 2.90 & 4.60 & $\begin{array}{c}\text { Molecularly } \\
\text { dissolved }\end{array}$ \\
\hline Methylene chloride & 20.20 & 17.00 & 7.30 & 7.10 & $\begin{array}{c}\text { Molecularly } \\
\text { dissolved }\end{array}$ \\
\hline Ethyl alcohol & 26.20 & 15.80 & 8.80 & 19.40 & $\begin{array}{c}\text { Molecularly } \\
\text { dissolved }\end{array}$ \\
\hline Methyl alcohol & 29.70 & 14.70 & 12.30 & 22.30 & $\begin{array}{c}\text { Molecularly } \\
\text { dissolved }\end{array}$ \\
\hline Water & 48.00 & 15.50 & 16.00 & 42.30 & Self-assembly \\
\hline
\end{tabular}

The additional DLS study of $10 \mathrm{mg} / \mathrm{mL}$ polymer solutions prepared via direct dissolving in a number of solvents was carried out (for the full list of used solvents see Supporting Information Table S1). It was found that the copolymers P1-P6 are molecularly soluble in solvents with the 
$\delta_{\mathrm{p}}$ value below 14 . At the same time, the DLS study of di- and triblock copolymers solutions in dimethyl sulphoxide (DMSO, $\delta_{\mathrm{p}}=16.4$ ) demonstrates unimodal distributions with a mean $D_{h}$ value in a range of 150-200 nm (see Supporting Information Figure S4). This observation gives indirect support of our hypothesis that the analysis of the polar contribution of Hansen solubility parameter could be used for a first estimation of the self-assembly of fluorinated polyoxazoline copolymers.

\subsection{Nanoparticle morphology}

Small Angle Neutron Scattering (SANS) was used to probe the nanoparticles architecture and determine their molecular parameters. The use of SANS allows to get more information about small particles compared with DLS method.
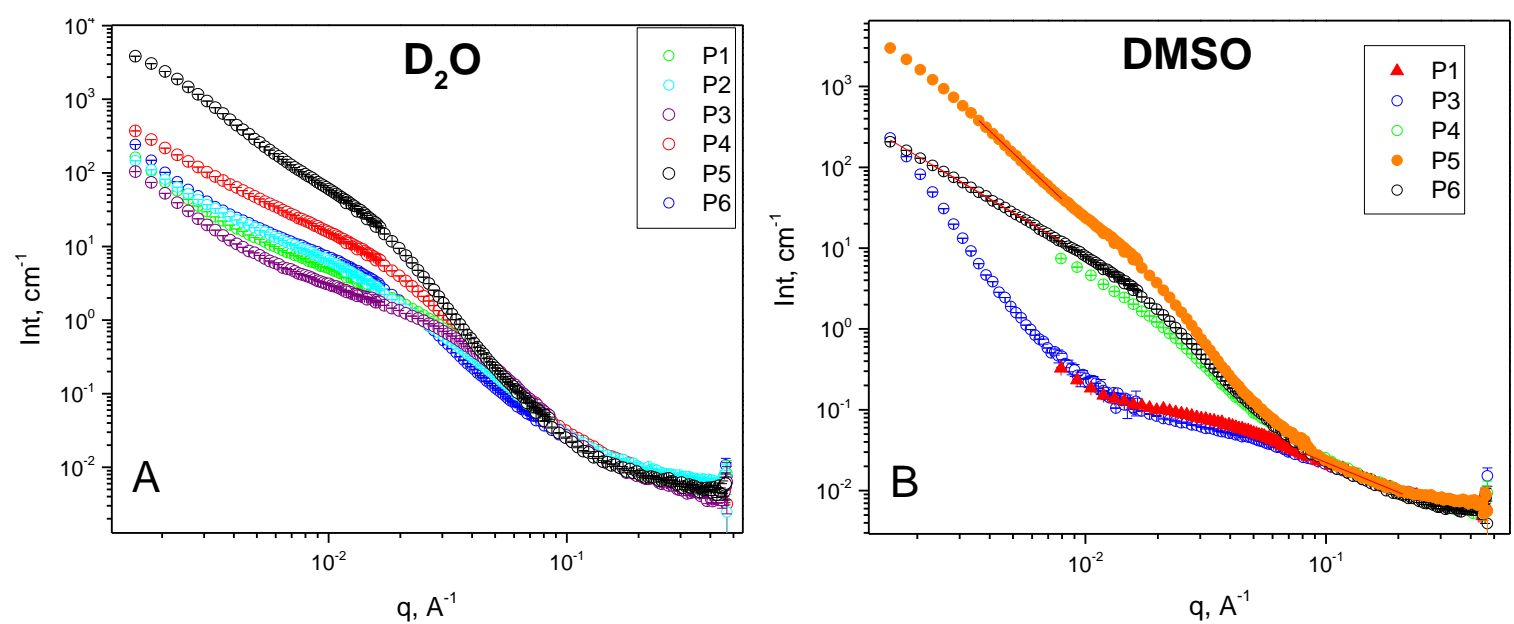

Figure 5. SANS curves for obtained polymers in $\mathrm{D}_{2} \mathrm{O}(\mathrm{A})$ and DMSO-d6 (B).

The copolymers solutions were prepared by direct dissolution in pure $\mathrm{D}_{2} \mathrm{O}$ and DMSO-d6. Under these conditions, the scattering from both core and shell is obtained as they are not matched with a particular solvent. The small $q$ value data for polymers P1 and P4 were not measured because of their similarity at middle and high $q$ ranges to P3 and P6 polymers, respectively.

The scattering curves obtained for the $\mathrm{D}_{2} \mathrm{O}$ solutions demonstrate similar shape and can be well fitted with the "Sphere with attached Gaussian chain" model, assuming a Schulz-Zimm distribution for shell thickness. Also, the contribution of large aggregates was added as a background to take into account the presence of polymersomes and increase the fit quality. The calculated structural parameters are presented in Table 3. 
Table 3. Comparison of structural parameters obtained from samples $\mathrm{P} 1-\mathrm{P} 6$ in $\mathrm{D}_{2} \mathrm{O}$

\begin{tabular}{|c|c|c|c|c|c|}
\hline & \multirow{2}{*}{ Composition } & \multirow{2}{*}{$\mathrm{R}_{\text {core }}(\mathrm{nm})$} & \multirow{2}{*}{$N_{\text {agg }}$} & \multicolumn{2}{|c|}{ Chain } \\
\hline & & & & $R_{\mathrm{g}}, \mathrm{nm}$ & $\sigma$ \\
\hline $\mathrm{P} 1$ & $\mathrm{MeOx}_{55}-\mathrm{R}_{\mathrm{f}}{ }^{6} \mathrm{EtOx}_{6}$ & 3.4 & 61 & 6.4 & 0.61 \\
\hline $\mathrm{P} 2$ & $\mathrm{MeOx}_{43}-\mathrm{R}_{\mathrm{f}}^{6} \mathrm{EtO}_{5}$ & 4.2 & 79 & 8.3 & 0.47 \\
\hline P3 & $\mathrm{MeOx}_{38}-\mathrm{R}_{\mathrm{f}}^{6} \mathrm{EtOx}_{5}$ & 3.0 & 54 & 6.1 & 0.74 \\
\hline P4 & $\mathrm{MeOx}_{45}-\mathrm{OctO}_{4}-\mathrm{R}_{\mathrm{f}}{ }^{6} \mathrm{EtOx}_{4}$ & 6.1 & 103 & 6.4 & 0.27 \\
\hline P5 & $\mathrm{OctO}_{7}-\mathrm{MeO}_{41}-\mathrm{R}_{\mathrm{f}}{ }^{6} \mathrm{EtO}_{4}$ & - & - & - & - \\
\hline P6 & $\mathrm{MeOx}_{55}-\mathrm{OctO}_{5}-\mathrm{R}_{\mathrm{f}}{ }^{6} \mathrm{EtO}_{4}$ & 6.0 & 55 & 6.0 & 0.34 \\
\hline
\end{tabular}

The obtained value of the core radii and shell thickness are in the range of 18-24 nm, which is in agreement with the $R_{\mathrm{h}}$ as observed in the DLS measurements and cryo-TEM. Unfortunately, the overall correlation between the diblock copolymer structural parameters and the polymer composition could not be achieved, mainly because of high polydispersity of the hydrophilic shell. Nevertheless, the significant increase of the mean micellar core radius with introduction of the OctOx hydrophobic block can be observed (from 3.5 to $6 \mathrm{~nm}$ ). This observation indicates the coexistence of the lipophilic and fluorophilic fragments in the core.

Unlike to aqueous solutions, the $\mathrm{MeOx}-\mathrm{R}_{\mathrm{f}}{ }^{6} \mathrm{EtOx}$ diblock copolymers were found to be molecularly dissolved in DMSO-d6 (Figure 5 B). The disagreement between SANS and DLS data where peaks with $100-200 \mathrm{~nm}$ were only present on a distribution function is explained by the high sensitivity of DLS to the presence of large aggregates, which obstruct the small particles detection. The successful fitting for copolymers P1 and P3 in DMSO-d6 was achieved using "Generalised Gaussian coil" model (Table 4) with a contribution of the large aggregates as a background. It could be concluded from the high value of the Flory parameter $v$ that DMSO is a "good solvent" for these polymers. The $v$ values of 0.75 and 0.93 imply that macromolecules exist in highly extended conformation that could be explained by the intrinsic rigidity of the fluorinated block.

Table 4. The structural parameters obtained for diblock copolymers P1 and P3 in DMSO-d6 using the "Generalised Gaussian coil" model. 


\begin{tabular}{|c|c|c|c|}
\hline & Composition & $R_{\mathrm{g}}, \mathrm{nm}$ & $v$ \\
\hline $\mathrm{P} 1$ & $\mathrm{MeO}_{55}-\mathrm{R}_{\mathrm{f}}^{6} \mathrm{EtOx}_{6}$ & 4.4 & $0.74 \pm 0.02$ \\
\hline P3 & $\mathrm{MeOx}_{38}-\mathrm{R}_{\mathrm{f}}^{6} \mathrm{EtOx}_{5}$ & 8 & $0.93 \pm 0.05$ \\
\hline
\end{tabular}

In contrast, the shape of the SANS curves of the triblock copolymers P4-P6 in DMSO-d6 indicates the presence of aggregates (Figure 5B). This observation implies that the hydrophobic POctOx block is mainly responsible for the self-assembly in DMSO. The scattering data could well be fitted using the monodisperse "Sphere with attached Gaussian chains" model (Table 4).

Table 5. The structural parameters obtained for triblock copolymers P4, P5 and P6 in DMSO-d6 using "Sphere with attached Gaussian chains" model.

\begin{tabular}{c|c|c|c|c}
\hline & Composition & $R_{\text {core }}, \mathrm{nm}$ & $R_{\mathrm{g}}, \mathrm{nm}$ & $\mathrm{N}_{\mathrm{agg}}$ \\
\hline P4 & $\mathrm{MeOx}_{45}-\mathrm{OctO}_{4}-\mathrm{R}_{\mathrm{f}}^{6} \mathrm{EtOx}_{4}$ & 6.3 & 3.4 & 37 \\
P5 & OctOx$_{7-\mathrm{MeOx}_{41}-\mathrm{R}_{\mathrm{f}}^{6} \mathrm{EtOx}_{4}}$ & 7.5 & 4.7 & 100 \\
P6 & $\mathrm{MeOx}_{55}-\mathrm{OctO}_{5}-\mathrm{R}_{\mathrm{f}}^{6} \mathrm{EtOx}_{4}$ & 7.5 & 6.2 & 69
\end{tabular}

The mean aggregates radii in DMSO is $20-26 \mathrm{~nm}$, which is in the same range as in $\mathrm{D}_{2} \mathrm{O}$ solutions. It also can be seen that the change in the location of the hydrophobic block affects the size of the aggregates: the P5 copolymer with lipophilic end block forms larger aggregates than the P4 copolymer of similar composition with lipophilic block in the middle. Such effect of the block order was previously observed only for aqueous solutions. ${ }^{46}$

The core radii of P4 and P6 aggregates also have the similar values in $\mathrm{D}_{2} \mathrm{O}$ and in DMSO-d6. Therefore it is proposed that in DMSO-d6 the core is also composed of both lipophilic and fluorophilic blocks, despite the affinity of the last one to DMSO. Such ordering could be explained by the strong interactions between alkyl fragments in lipophilic layer and short length of the fluorophilic block.

The difference in solution behavior of polymers P1-P6 in water and DMSO could be explained by comparison of their Hansen polarity $\left(\delta_{\mathrm{p}}\right)$ and hydrogen bonds $\left(\delta_{\mathrm{h}}\right)$ contributions. Indeed, $\mathrm{MeOx}$ has the highest polarity, while OctOx is almost nonpolar. The presence of these blocks in one macromolecule produces high non-homogeneity in polarity and facilitates self-assembly 
in polar water and DMSO. Also, this contrast is enhanced by the difference in ability to Hbonding, which is much stronger for $\mathrm{PMeOx}$ then for POctOx. At the same time, $\mathrm{PR}_{\mathrm{f}}{ }^{6} \mathrm{EtOx}$ possesses noticeable polarity due to its structure, but still has low ability to form H-bonds. ${ }^{10}$ Therefore, we can assume that $\mathrm{PMeOx}-b-\mathrm{PR}_{\mathrm{f}}{ }^{6} \mathrm{EtOx}$ diblock copolymers form micelles in aqueous solution, whereas in DMSO, where H-bonding effect is much lower; they are molecularly dissolved.

\section{Conclusion}

In this paper we tested a several approaches for the synthesis of highly fluorinated 2-oxazolines. The only successful route was the Wanker method supplemented by the Grignard synthesis of fluorinated carboxylic acid. According to this approach 2- $(1 \mathrm{H}, 1 \mathrm{H}, 2 \mathrm{H}, 2 \mathrm{H}$-perfluorooctyl)-2oxazoline monomer was synthesized. The polymerization kinetics study demonstrated the complete suppression of deceleration effect of perfluoroalkyl group by the insertion of double methylene spacer leading to good monomer reactivity in the Cationic Ring-Opening Polymerization.

A series of di- and triblock copolymers based on 2-(1H,1H,2H,2H-perfluorooctyl)-2-oxazoline, 2-methyl-2-oxazoline and 2-n-octyl-2-oxazoline were synthesized. Well-defined copolymers with $M_{\mathrm{n}}$ in the range of 5300-7300 and $Ð$ in the range of 1.2-1.4 were obtained. DLS revealed the ability of the synthesized copolymers to self-assemble in aqueous milieu and in DMSO. The presence of micelle-like aggregates and polymersomes in aqueous solutions was visualized by Cryo-TEM.

Further investigation of the nanoparticle morphologies was done by SANS revealing that the presence of both the POctOx and the $\mathrm{PR}_{\mathrm{f}}{ }^{6} \mathrm{EtOx}$ blocks results in the formation of nanoparticles with a core-shell structure in aqueous solutions of both di- and triblock copolymers, whereas in DMSO the presence of the POctOx block is required for the self-assembly. It was also found that in DMSO the block order has an influence on the aggregate size and structure in the same way as it was observed for aqueous solutions. The importance of Hansen polarity contribution is revealed for self-assembly of these fluorinated copolymers.

The obtained polymers represent a potential platform for application as ${ }^{19} \mathrm{~F}$ magnetic resonance imaging contrast agents, which will be the focus of our future work. 


\section{Acknowledgment}

SF and RH acknowledge the support of the mobility project AV ČR - FWO, FWO-17-05. SF acknowledge the support of the Czech Science Foundation GACR (grant 17-00973S). FRM II (Garching) is acknowledged for beam time allocation. LK acknowledges Konefal Rafal and Velychkivska Nadiia (Institute of Macromolecular Chemistry AS CR, v.v.i., Prague, Czech Republic) for help with the NMR studies. SF, LK, and AR acknowledge Eva Miskovska for refractive index increment measurements, and Bedrich Porsch and Zuzana Masinova (Institute of Macromolecular Chemistry AS CR, v.v.i., Prague, Czech Republic) for polymer characterization by GPC. BV and RH acknowledge support from the institute for innovation and technology (IWT), Flanders for funding. The cryo-TEM work was performed by Judith Scmmidt at the Technion Center for Electron Microscopy of Soft Matter, supported by the Technion Russell Berri Nanotechnology Institute (RBNI).

\section{References}

(1) Kagiya, T.; Maeda, T.; Fukui, K.; Narisawa, S. Ring Opening Polymerization Of 2Substituted 2-Oxazolines. Polym. Lett. 1966, 4, 441-445 DOI:

10.1002/pol.1966.110040701.

(2) Seeliger, W.; Aufderhaar, E.; Diepers, W.; Feinauer, R.; Nehring, R.; Thier, W.; Hellmann, H. Recent Syntheses and Reactions of Cyclic Imidic Esters. Angew. Chemie Int. Ed. English 1966, 5 (10), 875-888 DOI: 10.1002/anie.196608751.

(3) Tomalia, D. A.; Sheetz, D. P. Homopolymerization of 2-Alkyl- and 2-Aryl-2Oxazolines. J. Polym. Sci. Part A-1 Polym. Chem. 1966, 4 (9), 2253-2265 DOI: 10.1002/pol.1966.150040919.

(4) Levy, A.; Litt, M. Polymerization of Cyclic Imino Ethers. II. Oxazines. J. Polym. Sci. Part B Polym. Lett. 1967, 5 (9), 881-886 DOI: 10.1002/pol.1967.110050928.

(5) Luxenhofer, R.; Schulz, A.; Roques, C.; Li, S.; Bronich, T. K.; Batrakova, E. V.; Jordan, R.; Kabanov, A. V. Doubly Amphiphilic Poly(2-Oxazoline)s as High-Capacity 
Delivery Systems for Hydrophobic Drugs. Biomaterials 2010, 31 (18), 4972-4979 DOI: 10.1016/j.biomaterials.2010.02.057.

(6) Filippov, S. K.; Bogomolova, A.; Kaberov, L.; Velychkivska, N.; Starovoytova, L.; Cernochova, Z.; Rogers, S. E.; Lau, W. M.; Khutoryanskiy, V. V.; Cook, M. T. Internal Nanoparticle Structure of Temperature-Responsive Self-Assembled PNIPAM-b-PEGb-PNIPAM Triblock Copolymers in Aqueous Solutions: NMR, SANS, and Light Scattering Studies. Langmuir 2016, 32 (21), 5314-5323 DOI:

10.1021/acs.langmuir.6b00284.

(7) Vishnevetskaya, N. S.; Hildebrand, V.; Niebuur, B.-J.; Grillo, I.; Filippov, S. K.; Laschewsky, A.; Müller-Buschbaum, P.; Papadakis, C. M. Aggregation Behavior of Doubly Thermoresponsive Polysulfobetaine- b -Poly( N -Isopropylacrylamide) Diblock Copolymers. Macromolecules 2016, 49 (17), 6655-6668 DOI:

10.1021/acs.macromol.6b01186.

(8) Filippov, S. K.; Verbraeken, B.; Konarev, P. V.; Svergun, D. I.; Angelov, B.; Vishnevetskaya, N. S.; Papadakis, C. M.; Rogers, S.; Radulescu, A.; Courtin, T.; Martins, J. C.; Starovoytova, L.; Hruby, M.; Stepanek, P.; Kravchenko, V. S.; Potemkin, I. I.; Hoogenboom, R. Block and Gradient Copoly(2-Oxazoline) Micelles: Strikingly Different on the Inside. J. Phys. Chem. Lett. 2017, 8 (16), 3800-3804 DOI: 10.1021/acs.jpclett.7b01588.

(9) Filippov, S. K.; Starovoytova, L.; Koňák, Č.; Hrubý, M.; MacKová, H.; Karlsson, G.; Štěpánek, P. PH Sensitive Polymer Nanoparticles: Effect of Hydrophobicity on SelfAssembly. Langmuir 2010, 26 (18), 14450-14457 DOI: 10.1021/la1018778.

(10) Krafft, M. P.; Riess, J. G. Chemistry, Physical Chemistry, and Uses of Molecular Fluorocarbon- Hydrocarbon Diblocks, Triblocks, and Related Compounds-Unique “Apolar" Components for Self-Assembled Colloid and Interface Engineering. Chem. Rev. 2009, 109 (5), 1714-1792 DOI: 10.1021/cr800260k.

(11) Liu, W.; Frank, J. A. Detection and Quantification of Magnetically Labeled Cells by Cellular MRI. Eur. J. Radiol. 2009, 70 (2), 258-264 DOI: 10.1016/j.ejrad.2008.09.021.

(12) Boehm-Sturm, P.; Mengler, L.; Wecker, S.; Hoehn, M.; Kallur, T. In Vivo Tracking of Human Neural Stem Cells with 19F Magnetic Resonance Imaging. PLoS One 2011, 6 
(12) DOI: 10.1371/journal.pone.0029040.

(13) Srinivas, M.; Heerschap, A.; Ahrens, E. T.; Figdor, C. G.; de Vries, I. J. M. 19F MRI for Quantitative in Vivo Cell Tracking. Trends Biotechnol. 2010, 28 (7), 363-370 DOI: 10.1016/j.tibtech.2010.04.002.

(14) Li, Z.; Kesselman, E.; Talmon, Y.; Hillmyer, M. A.; Lodge, T. P. Multicompartment Micelles from ABC Miktoarm Stars in Water. Science (80-. ). 2004, 306 (5693), 98101 DOI: $10.1126 /$ science. 1103350.

(15) Kubowicz, S.; Baussard, J. F.; Lutz, J. F.; Thünemann, A. F.; Von Berlepsch, H.; Laschewsky, A. Multicompartment Micelles Formed by Self-Assembly of Linear ABC Triblock Copolymers in Aqueous Medium. Angew. Chemie - Int. Ed. 2005, 44 (33), 5262-5265 DOI: 10.1002/anie.200500584.

(16) Kotzev, A.; Laschewsky, A.; Rakotoaly, R. H. Polymerizable Surfactants and Micellar Polymers Bearing Fluorocarbon Hydrophobic Chains Based on Styrene. Macromol. Chem. Phys. 2001, 202 (17), 3257-3267 DOI: 10.1002/15213935(20011101)202:17<3257::AID-MACP3257>3.0.CO;2-P.

(17) Berlepsch, H. V.; Böttcher, C.; Skrabania, K.; Laschewsky, A. Complex Domain Architecture of Multicompartment Micelles from a Linear ABC Triblock Copolymer Revealed by Cryogenic Electron Tomography. Chem. Commun. 2009, No. 17, 2290 DOI: $10.1039 / \mathrm{b} 903658 \mathrm{j}$.

(18) Laschewsky, A.; Marsat, J. N.; Skrabania, K.; Von Berlepsch, H.; Böttcher, C. Bioinspired Block Copolymers: Translating Structural Features from Proteins to Synthetic Polymers. Macromol. Chem. Phys. 2010, 211 (2), 215-221 DOI: 10.1002/macp.200900378.

(19) Skrabania, K.; Laschewsky, A.; Berlepsch, H. V.; Böttcher, C. Synthesis and Micellar Self-Assembly of Ternary Hydrophilic- Lipophilicfluorophilic Block Copolymers with a Linear PEO Chain. Langmuir 2009, 25 (13), 7594-7601 DOI: 10.1021/la900253j.

(20) Skrabania, K.; Berlepsch, H. V.; Böttcher, C.; Laschewsky, A. Synthesis of Ternary, Hydrophilic-Lipophilic-Fluorophilic Block Copolymers by Consecutive RAFT Polymerizations and Their Self-Assembly into Multicompartment Micelles. Macromolecules 2010, 43 (1), 271-281 DOI: 10.1021/ma901913f. 
(21) Matsumoto, K.; Nishimura, R.; Mazaki, H.; Matsuoka, H.; Yamaoka, H. Synthesis and Hydrogel Formation of Fluorine-Containing Amphiphilic ABA Triblock Copolymers. J. Polym. Sci. Part A Polym. Chem. 2001, 39 (21), 3751-3760 DOI: 10.1002/pola.10011.

(22) Guo, W.; Tang, X.; Xu, J.; Wang, X.; Chen, Y.; Yu, F.; Pei, M. Synthesis, Characterization, and Property of Amphiphilic Fluorinated ABC-Type Triblock Copolymers. J. Polym. Sci. Part A Polym. Chem. 2011, 49 (7), 1528-1534 DOI: 10.1002/pola.24573.

(23) Chen, J.; Li, J. J.; Luo, Z. H. Synthesis, Surface Property, Micellization and PH Responsivity of Fluorinated Gradient Copolymers. J. Polym. Sci. Part A Polym. Chem. 2013, 51 (5), 1107-1117 DOI: 10.1002/pola.26473.

(24) Miyamoto, M.; Aoi, K.; Saegusa, T. Novel Covalent-Type Electrophilic Polymerization of 2-(Perfluoroalkyl)-2-Oxazolines Initiated by Sulfonates. Macromolecules 1991, 24 (1), 11-16 DOI: 10.1021/ma00001a002.

(25) Ivanova, R.; Komenda, T.; Bonné, T. B.; Lüdtke, K.; Mortensen, K.; Pranzas, P. K.; Jordan, R.; Papadakis, C. M. Micellar Structures of Hydrophilic/Lipophilic and Hydrophilic/Fluorophilic Poly(2-Oxazoline) Diblock Copolymers in Water. Macromol. Chem. Phys. 2008, 209 (21), 2248-2258 DOI: 10.1002/macp.200800232.

(26) Miyamoto, M.; Aoi, K.; Saegusa, T. Poly[(Acylimino)Alkylene] Block Copolymers Having Perfluoroalkyl Hydrophobic Blocks. Synthesis and Surfactant Properties. Macromolecules 1989, 22 (9), 3540-3543 DOI: 10.1021/ma00199a007.

(27) Weberskirch, R.; Preuschen, J.; Spiess, H. W.; Nuyken, O. Design and Synthesis of a Two Compartment Micellar System Based on the Self-Association Behavior of Poly(N-Acylethyleneimine) End-Capped with a Fluorocarbon and a Hydrocarbon Chain. Macromol.Chem.Phys. 2000, 201 (10), 995-1007 DOI: 10.1002/15213935(20000601)201:10<995::AID-MACP995>3.0.CO;2-T.

(28) Kubowicz, S.; Thünemann, A. F.; Weberskirch, R.; Möhwald, H. Cylindrical Micelles of $\alpha$-Fluorocarbon- $\omega$-Hydrocarbon End-Capped Poly( N -Acylethylene Imine)S. Langmuir 2005, 21 (16), 7214-7219 DOI: 10.1021/la050987o.

(29) Kaberov, L. I.; Verbraeken, B.; Hruby, M.; Riabtseva, A.; Kovacik, L.; Kereiche, S.; 
Brus, J.; Stepanek, P.; Hoogenboom, R.; Filippov, S. K. Novel Triphilic Block Copolymers Based on Poly(2-Methyl-2-Oxazoline)-Block-Poly(2-Octyl-2-Oxazoline) with Different Terminal Perfluoroalkyl Fragments: Synthesis and Self-Assembly Behaviour. Eur. Polym. J. 2017, 88, 645-655 DOI: 10.1016/j.eurpolymj.2016.10.016.

(30) Lobert, M.; Thijs, H. M. L.; Erdmenger, T.; Eckardt, R.; Ulbricht, C.; Hoogenboom, R.; Schubert, U. S. Synthesis, Microwave-Assisted Polymerization, and Polymer Properties of Fluorinated 2-Phenyl-2-Oxazolines: A Systematic Study. Chem. - A Eur. J. 2008, 14 (33), 10396-10407 DOI: 10.1002/chem.200800671.

(31) Kempe, K.; Hoogenboom, R.; Hoeppener, S.; Fustin, C.-A.; Gohy, J.-F.; Schubert, U. S. Discovering New Block Terpolymer Micellar Morphologies. Chem. Commun. 2010, 46 (35), 6455 DOI: 10.1039/c001629b.

(32) Kaberov, L. I.; Verbraeken, B.; Riabtseva, A.; Brus, J.; Talmon, Y.; Stepanek, P.; Hoogenboom, R.; Filippov, S. K. Fluorinated 2-Alkyl-2-Oxazolines of High Reactivity: Spacer-Length-Induced Acceleration for Cationic Ring-Opening Polymerization As a Basis for Triphilic Block Copolymer Synthesis. ACS Macro Lett. 2017, 7-10 DOI: 10.1021/acsmacrolett.7b00954.

(33) Baker, R. J.; McCabe, T.; O’Brien, J. E.; Ogilvie, H. V. Thermomorphic Metal Scavengers: A Synthetic and Multinuclear NMR Study of Highly Fluorinated Ketones and Their Application in Heavy Metal Removal. J. Fluor. Chem. 2010, 131 (5), 621626 DOI: 10.1016/j.jfluchem.2010.02.004.

(34) Petrova, S.; Klepac, D.; Konefał, R.; Kereïche, S.; Kováčik, L.; Filippov, S. K. Synthesis and Solution Properties of PCL-b-PHPMA Diblock Copolymers Containing Stable Nitroxyl Radicals. Macromolecules 2016, 49 (15), 5407-5417 DOI: 10.1021/acs.macromol.6b01187.

(35) Trousil, J.; Filippov, S. K.; Hrubý, M.; Mazel, T.; Syrová, Z.; Cmarko, D.; Svidenská, S.; Matějková, J.; Kováčik, L.; Porsch, B.; Konefał, R.; Lund, R.; Nyström, B.; Raška, I.; Štěpánek, P. System with Embedded Drug Release and Nanoparticle Degradation Sensor Showing Efficient Rifampicin Delivery into Macrophages. Nanomedicine Nanotechnology, Biol. Med. 2017, 13 (1), 307-315 DOI: 10.1016/j.nano.2016.08.031.

(36) Radulescu, A.; Szekely, N. K.; Appavou, M.-S. KWS-2: Small Angle Scattering 
Diffractometer. J. large-scale Res. Facil. JLSRF 2015, 1, A29 DOI: 10.17815/jlsrf-127.

(37) Breßler, I.; Kohlbrecher, J.; Thünemann, A. F. SASfit: A Tool for Small-Angle Scattering Data Analysis Using a Library of Analytical Expressions. J. Appl. Crystallogr. 2015, 48, 1587-1598 DOI: 10.1107/S1600576715016544.

(38) Witte, H.; Seeliger, W. Cyclische Imidsaureester Aus Nitrilen Und Aminoalkoholen. Justus Liebigs Ann. Chem. 1974, 1974 (6), 996-1009 DOI:

10.1002/jlac.197419740615.

(39) Verbraeken, B.; Lava, K.; Hoogenboom, R. Poly ( 2-Oxazoline ) S. Encycl. Polym. Sci. Technol. 2014, No. 1, 1-51.

(40) Persigehl, P.; Jordan, R.; Nuyken, O. Functionalization of Amphiphilic Poly(2Oxazoline) Block Copolymers: A Novel Class of Macroligands for Micellar Catalysis. Macromolecules 2000, 33 (19), 6977-6981 DOI: 10.1021/ma0007381.

(41) Taubmann, C.; Luxenhofer, R.; Cesana, S.; Jordan, R. First Aldehyde-Functionalized Poly(2-Oxazoline)s for Chemoselective Ligation. Macromol. Biosci. 2005, 5 (7), $603-$ 612 DOI: 10.1002/mabi.200500059.

(42) Wenker, H. The Synthesis of $\Delta 2$-Oxazolines and $\Delta 2$-Thiazolines from N-Acyl-2Aminoethanols. J. Am. Chem. Soc. 1935, 57 (6), 1079-1080 DOI:

10.1021/ja01309a034.

(43) Wiesbrock, F.; Hoogenboom, R.; Leenen, M. A. M.; Meier, M. A. R.; Schubert, U. S. Investigation of the Living Cationic Ring-Opening Polymerization of 2-Methyl-, 2Ethyl-, 2-Nonyl-, and 2-Phenyl-2-Oxazoline in a Single-Mode Microwave Reactor. Macromolecules 2005, 38 (12), 5025-5034 DOI: 10.1021/ma0474170.

(44) Verbraeken, B.; Monnery, B. D.; Lava, K.; Hoogenboom, R. The Chemistry of Poly(2Oxazoline)S. Eur. Polym. J. 2017, 88, 451-469 DOI:

10.1016/j.eurpolymj.2016.11.016.

(45) Hansen, C. M. Hansen Solubility Parameters A User's Handbook; 2007.

(46) Hoogenboom, R.; Wiesbrock, F.; Huang, H.; Leenen, M. A. M.; Thijs, H. M. L.; Van Nispen, S. F. G. M.; Van Der Loop, M.; Fustin, C. A.; Jonas, A. M.; Gohy, J. F.; 
Schubert, U. S. Microwave-Assisted Cationic Ring-Opening Polymerization of 2-

Oxazolines: A Powerful Method for the Synthesis of Amphiphilic Triblock

Copolymers. Macromolecules 2006, 39 (14), 4719-4725 DOI: 10.1021/ma060952a. 
Fluorophilic-lipophilic-hydrophilic poly-2-oxazolines block copolymers as MRI contrast agents: from synthesis to self-assembly

Leonid I. Kaberov ${ }^{1}$, Bart Verbraeken ${ }^{2}$, Anna Riabtseva ${ }^{1}$, Jiri Brus ${ }^{1}$, Aurel Radulescu ${ }^{3}$, Yeshayahu Talmon ${ }^{4}$, Petr Stepanek ${ }^{1}$, Richard Hoogenboom ${ }^{2}$, Sergey K. Filippov ${ }^{{ }^{*}}$

${ }^{1}$ Institute of Macromolecular Chemistry, Academy of Sciences of the Czech Republic, Heyrovský Sq. 2, 16206 Prague 6, Czech Republic

${ }^{2}$ Supramolecular Chemistry Group, Centre of Macromolecular Chemistry (CMaC), Department of Organic and Macromolecular Chemistry, Ghent University, Krijgslaan 281 S4, B-9000 Ghent, Belgium

${ }^{3}$ Forschungszentrum Jülich GmbH, Jülich Centre for Neutron Science JCNS, Outstation at Heinz Maier-Leibnitz, Zentrum, Lichtenbergstraße 1, 85748 Garching, Germany

${ }^{4}$ Department of Chemical Engineering, Technion-Israel Institute of Technology, Haifa 3200003, Israel

*e-mail: filippov@imc.cas.cz

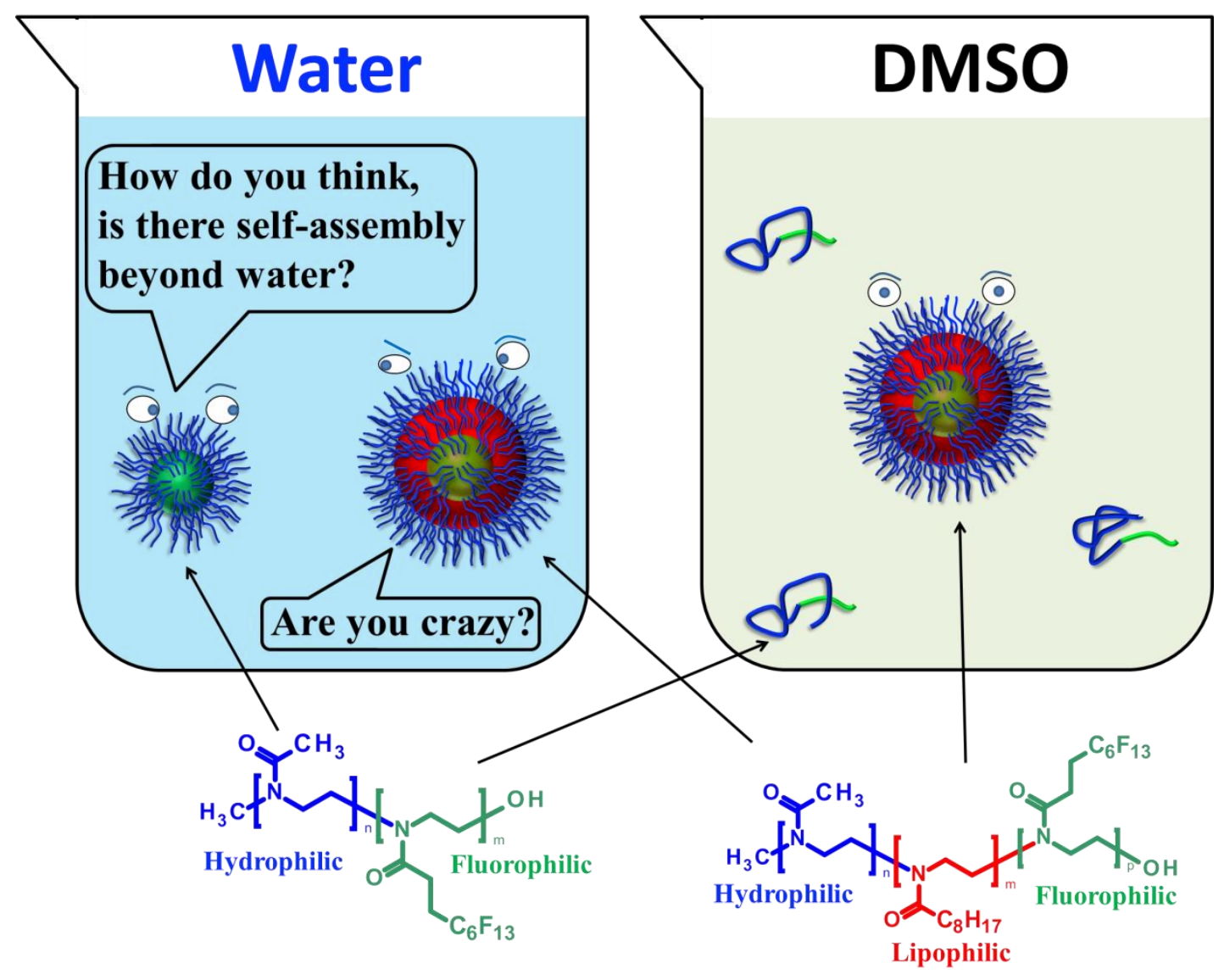

